\title{
Operando Determination of the Thermal Decomposition of Supported Ionic Liquids by a Radio-Frequency-Based Method
}

\author{
Marie-Luise Anke, ${ }^{*},+\odot$ Martin Hämmerle, ${ }^{\ddagger}$ Ralf Moos, ${ }^{\ddagger}$ and Andreas Jess ${ }^{\dagger}$ \\ ${ }^{\dagger}$ Department of Chemical Engineering and Department of Functional Materials, University of Bayreuth, Universitätsstraße 30, \\ 95447 Bayreuth, Germany
}

\section{Supporting Information}

ABSTRACT: The analysis of the thermal stability of supported ionic liquids (ILs) is of great interest for their application in catalysis. However, thermogravimetric (TG) measurements are very time-consuming, destructive, and cannot be conducted operando. Therefore, a new radio-frequency (RF)based method is presented that analyzes the electrical properties of supported ILs in the microwave range and can detect a possible IL mass loss caused by evaporation or decomposition. In this study, the decomposition of supported 1-butyl-3-methylimidazolium dimethylphosphate ([BMIM][DMP]) with and without palladium (as an active metal) is investigated operando during the selective hydrogenation of 1,3-butadiene. In addition to volatile decomposition products, solid products are formed, which remain on the carrier. These solid products impair the activity of the Pd catalyst. Using the RF-based method, a distinction can be made between "intact" IL and the solid decomposition

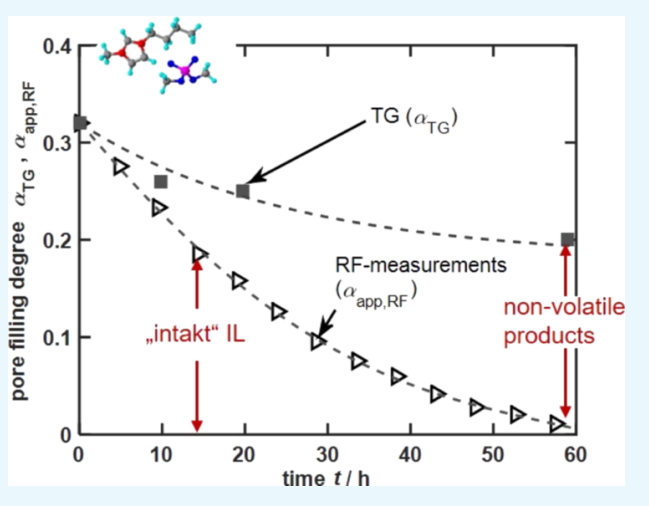
products because the electrical properties of both substances differ substantially. In contrast, the destructive TG analysis only measures the mass loss by the formation of gaseous decomposition products and thus cannot distinguish between "intact" IL and the solid decomposition products of [BMIM] [DMP]. In addition, a model of the thermal decomposition which depicts the measured mass losses well is presented.

\section{INTRODUCTION}

Ionic liquids (ILs) are pure molten salts ${ }^{1}$ with a melting point below $100{ }^{\circ} \mathrm{C}{ }^{2,3}$ Because they are mostly expensive, several immobilization methods have been developed in recent years for their economical use in catalysis, ${ }^{4}$ for example, the supported IL phase (SILP)-concept and the supported catalyst with IL layer (SCILL)-concept. ${ }^{5}$ In the SILP-concept, a homogeneous catalyst is dissolved in an IL and immobilized on a porous carrier. ${ }^{6}$ This facilitates product separation and also prevents mass-transport limitations. ${ }^{6}$ The SCILL-concept is based on the coating of a heterogeneous catalyst with an IL. ${ }^{7}$ This modifies the chemical and physical properties of the catalyst and optimizes the product distribution. ${ }^{7}$ For example, in the selective hydrogenation of butadiene to butene, the coating of a Pd catalyst with the IL 1-butyl-3-methylimidazolium dimethylphosphate, in short [BMIM][DMP], leads to an increase in selectivity to the desired intermediate butene. ${ }^{8,9}$ Further information on the two concepts can be found in ref 10.

For the application of supported ionic fluids, an exact knowledge of the thermal stability (mass loss due to evaporation and/or decomposition) of the IL layer is important. State of the art to analyze the stability of supported ILs is thermogravimetry (TG). ${ }^{5,11}$ However, TG measurements are destructive, ex situ, and they cannot be carried out under reaction conditions. ${ }^{12}$ Therefore, in this work, a radiofrequency (RF)-based method to determine the thermal stability with regard to the decomposition of the IL is presented. This method has already been successfully applied to determine the coke loading of heterogeneous catalysts ${ }^{13,14}$ as well as to measure quantitatively the ammonia sorption of SCR catalysts. ${ }^{15,16}$ Sulfur poisoning of Ni catalysts has been qualitatively determined as well. ${ }^{17}$ In a previous study, the evaporation rate of supported [EMIM] $\left[\mathrm{NTf}_{2}\right]$ could be determined using the RF-based method. ${ }^{18,19}$ In all of these applications, the electrical parameters such as the complex permittivity of the catalyst itself are analyzed. On the basis of the results, conclusions can be drawn about the state of the ILcoated catalyst.

The central part of the measurement setup is a cavity resonator. The sample (e.g., catalyst or supported IL) is introduced into the central axis of the cavity resonator, and an electromagnetic field is excited in the resonator. Changes in the electrical properties of the material under test affect the electromagnetic field. For example, a decrease of the IL pore filling degree $\alpha$, which is the ratio of the IL volume $V_{\mathrm{IL}}$ and the pore volume of the uncoated carrier $V_{\text {pore }, 0}$ (eq 1 ), reduces the dielectric and resistive losses (imaginary part of the complex permittivity) of the sample and changes the field distribution of the $E$-field. ${ }^{19}$

Received: September 18, 2018

Accepted: January 4, 2019

Published: February 14, 2019 

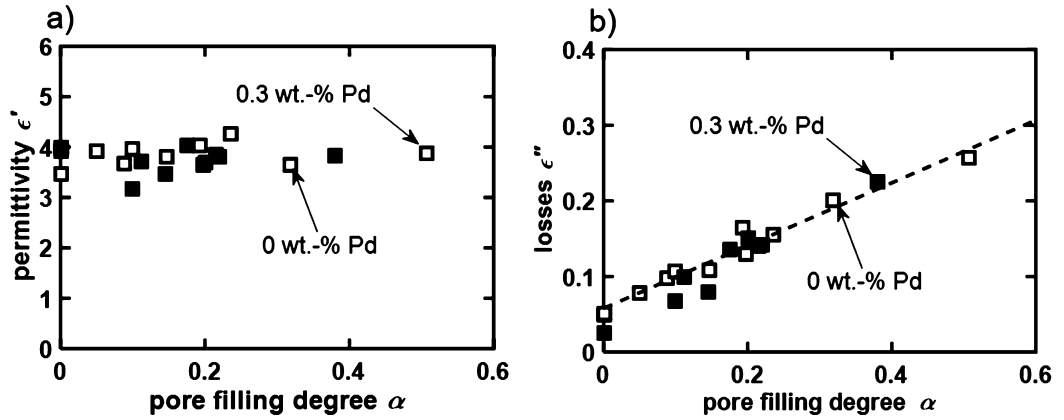

Figure 1. Real part of the complex permittivity $\varepsilon^{\prime}$ (a) and losses $\varepsilon^{\prime \prime}$ (b) at $20^{\circ} \mathrm{C}$ with (filled symbols) and without palladium (open symbols) as they depend on the pore filling degree $\alpha$.

$$
\alpha=\frac{V_{\mathrm{IL}}}{V_{\text {pore }, 0}}
$$

In this work, this technique is applied to measure the decomposition of supported ILs. The experiments are conducted operando during the hydrogenation of butadiene to butene. The IL [BMIM][DMP] is chosen for this purpose. This IL has a relatively low decomposition temperature of 137 ${ }^{\circ} \mathrm{C}$ (1\% mass loss per month), ${ }^{20}$ and its influence on the selectivity and activity of a Pd catalyst has already been investigated by Mangartz et al. ${ }^{9}$ Even a thin IL layer yields a butene selectivity of $100 \% .^{20}$ However, the activity of the catalyst is affected by the IL layer, i.e., the rate of butadiene hydrogenation decreases with increasing pore filling degree. ${ }^{20}$ Furthermore, the vapor pressure of [DMIM][DMP], a structurally very similar IL, is only $0.2 \mathrm{mPa}$ at $137{ }^{\circ} \mathrm{C} .{ }^{20}$ Therefore, it is expected that mass loss by evaporation is also negligible for [BMIM] [DMP] at this temperature. This matter $[\mathrm{BMIM}][\mathrm{DMP}]$ is the ideal IL for operando analysis of the thermal decomposition only and of the respective influence on the activity and selectivity of a SCILL-catalyst.

\section{RESULTS AND DISCUSSION}

RF Measurements of Supported [BMIM][DMP] with and without Palladium. Figure 1 shows (a) the real part of the complex permittivity $\varepsilon^{\prime}$ and (b) the losses $\varepsilon^{\prime \prime}$ as they depend on the pore filling degree $\alpha$ for supported [BMIM] [DMP] with and without palladium. The real part of the permittivity is influenced neither by the degree of pore filling nor by the low palladium content. The losses, on the other hand, increase linearly with the pore filling degree $\alpha$. Because of the low $\mathrm{Pd}$ content, the electrical signal $\varepsilon^{\prime \prime}$ is not influenced by the active component palladium. The relationship in Figure 1 for $20^{\circ} \mathrm{C}$ can be approximated by eq 2 .

$$
\varepsilon^{\prime \prime}=0.46 \cdot \alpha+0.05
$$

The losses $\varepsilon^{\prime \prime}$ of the pure carrier material at $20{ }^{\circ} \mathrm{C}$ are only 0.05 . Because of its ionic character, the IL exhibits significantly higher losses. For this reason, losses increase strongly with increasing IL content.

Analysis of the Thermal Decomposition of the IL by Thermogravimetric Investigation. The thermal decomposition of supported [BMIM][DMP] was further investigated in a thermobalance at temperatures of even up to $400{ }^{\circ} \mathrm{C}$. Figure 2 shows the result of a transient TG analysis in nitrogen atmosphere (normalized mass loss in Figure 2a and derivative in Figure 2b).

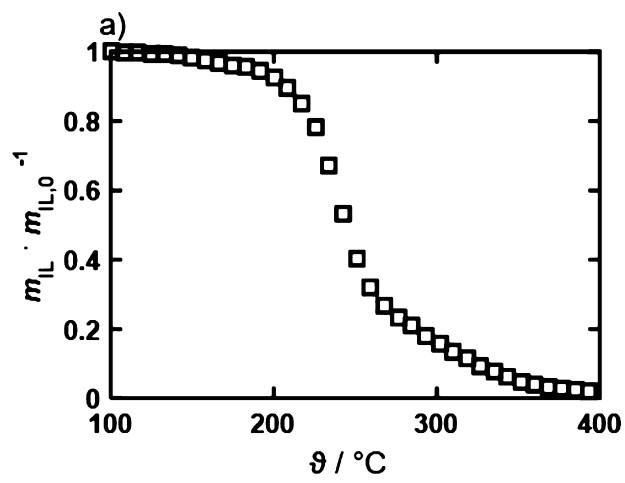

b)

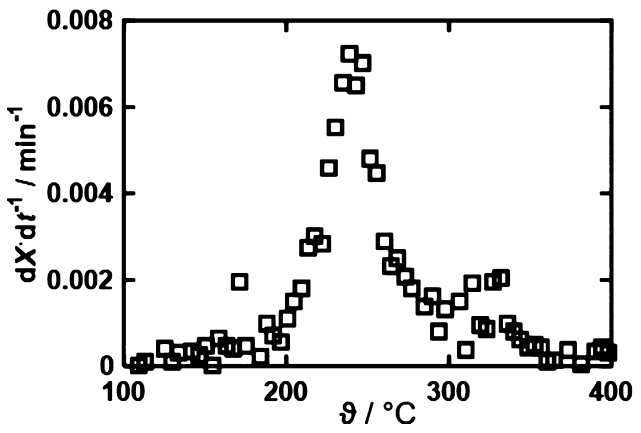

Figure 2. TG analysis of the thermal decomposition of supported [BMIM][DMP], (a) normalized IL mass loss and (b) its derivative; heating rate $=0.5 \mathrm{~K} \mathrm{~min}^{-1}, 300 \mathrm{~mL} \mathrm{~min}^{-1}$ nitrogen. Only individual measuring points instead of a curve were used to create a better distinction to the simulated results (e.g., Figure 8). For a better representation, a different number of measuring points have been entered in both diagrams.

Most of the mass loss occurs between 200 and $350{ }^{\circ} \mathrm{C}$. Two different processes can be distinguished (see Figure $2 b$ ).

The first process at $\theta<250{ }^{\circ} \mathrm{C}$ is attributed to the decomposition of IL [BMIM][DMP]. It is assumed that besides gaseous also liquid or solid products are formed. They remain on the surface. Because there are only one or a few molecule layers on the carrier, a distinction between liquid and solid states is difficult. In the following, the term solid products are used, although it could be a liquid product, as well. These solid products decompose at higher temperatures $\left(\theta>250^{\circ} \mathrm{C}\right)$ causing the second maxima in Figure $2 \mathrm{~b}$ (at around $320^{\circ} \mathrm{C}$ ).

A contribution of evaporation (instead of thermal decomposition) to the mass loss is negligible, as an additional TG measurement with helium as the carrier gas proves (see the Supporting Information). Because of different diffusion 

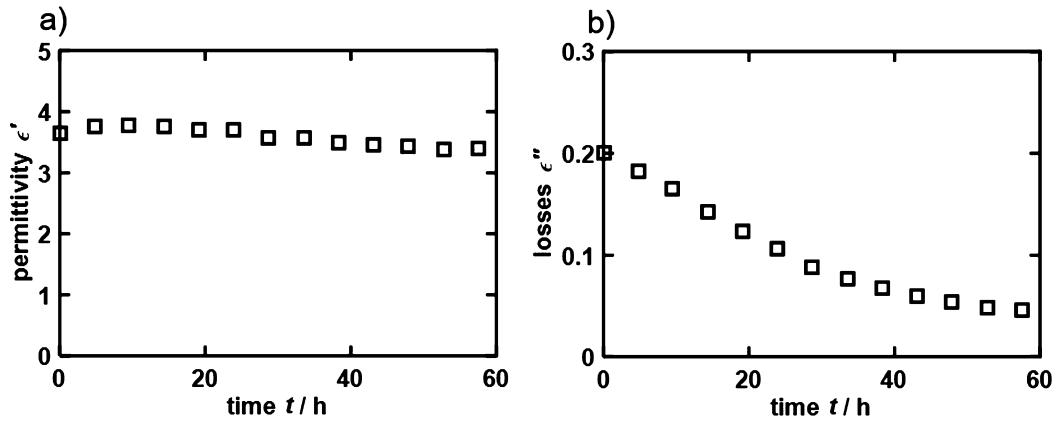

Figure 3. Course of the real part of the complex permittivity $\varepsilon^{\prime}$ (a) and the losses $\varepsilon^{\prime \prime}$ (b, measured at $20{ }^{\circ} \mathrm{C}$ ) during the thermal decomposition of supported [BMIM][DMP] $(0 \mathrm{wt} \% \mathrm{Pd})$ at $175^{\circ} \mathrm{C}$.

coefficients of the IL in helium and nitrogen, one would expect a different mass loss rate if the evaporation is rate limiting or at least contributes to the overall mass loss; however, that was not the case. ${ }^{5}$

RF-Based Analysis of the Thermal Decomposition of the Supported IL without Pd. Figure 3 depicts the course of $\varepsilon^{\prime}$ (Figure 3a) and the losses $\varepsilon^{\prime \prime}$ (Figure $3 \mathrm{~b}$ ) during the decomposition experiment of the supported [BMIM][DMP] (without palladium) at $175{ }^{\circ} \mathrm{C}$. Although $\varepsilon^{\prime}$ does not change significantly, $\varepsilon^{\prime \prime}$ decreases with increasing decomposition time $t$, but the decrease gets smaller with time.

From the measured values of the losses $\varepsilon^{\prime \prime}$ during the thermal decomposition of supported [BMIM][DMP] (Figure $1)$, the apparent pore filling degree $\alpha_{\mathrm{app}, \mathrm{RF}}$ can be calculated using eq 2 . In this context, the term apparent degree of pore filling is introduced because it is not known to what extent solid decomposition products are formed and whether they also contribute to the measured losses $\varepsilon^{\prime \prime}$. The constant permittivity during the test indicates that the IL does not decompose exclusively into gaseous products. According to eq 8 , the permittivity is also dependent on the sample volume. Therefore, a significant decrease of the sample volume would also cause a change of the permittivity. The effects of the sample volume on the losses are not as pronounced.

As discussed below, $\alpha_{\mathrm{app}, \mathrm{RF}}$ can be regarded as a good measure for the residual pore filling degree with intact IL. Figure 4 shows the apparent pore filling degree $\alpha_{\text {app,RF }}$ determined by the RF-based technique (triangles) during the decomposition experiment. In addition, the "real" pore filling degree $\alpha_{\mathrm{TG}}$ as it is calculated on the basis of the mass loss measured in a thermobalance (squares) is shown. Up to a decomposition time of $10 \mathrm{~h}$, the values of the RF measurements correspond with the results of the TG analysis. After that, the pore filling degree $\alpha_{\mathrm{TG}}$, calculated from the mass loss in a thermobalance, decreases only slightly. After $60 \mathrm{~h}$, a pore filling degree of $20 \%$ can still be determined with the TG, whereas the apparent degree of pore filling is continuously decreasing to $0 \%$ using the RF-based method. The large difference between the pore filling degrees at $t=60 \mathrm{~h}$ determined by TG and RF measurement indicates the formation of solid decomposition products. These decomposition products may remain on the porous carrier during the decomposition of [BMIM][DMP].

In the thermobalance, the solid decomposition products are burned away with air by much higher temperatures than the used $175{ }^{\circ} \mathrm{C}$. Thus, by TG, the content of "intact" IL is overestimated because TG determines the total mass loss and cannot distinguish between the solid decomposition products

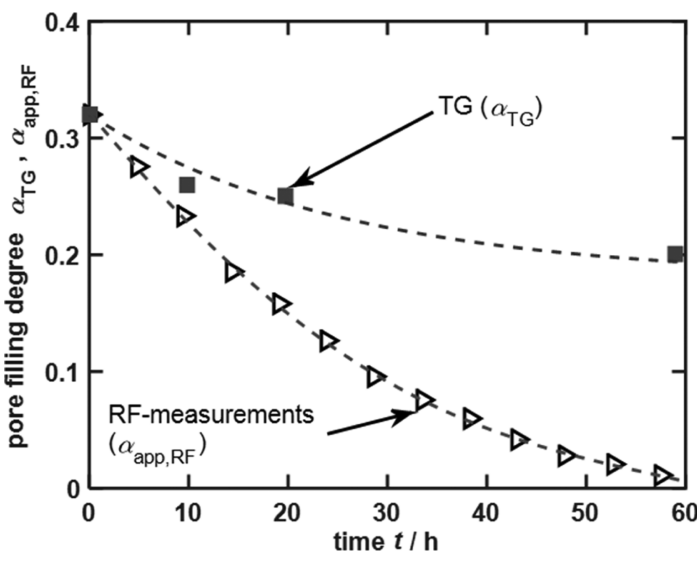

Figure 4. Pore filling degree during the thermal decomposition of supported [BMIM] [DMP] at $175^{\circ} \mathrm{C}$, measured every $5 \mathrm{~h}$ at $20^{\circ} \mathrm{C}$ by the RF-based method $\left(\alpha_{\mathrm{app}, \mathrm{RF}}\right)$ and at selected times by thermogravimetric measurements $\left(\alpha_{\mathrm{TG}}\right)$. For the TG analyses, each run $(10,20$, and $60 \mathrm{~h}$ ) had to be stopped and the entire sample had to be removed. Accordingly, a total of three independent runs was carried out, each with an identical, initial pore filling degree; only during the longest of these runs $(60 \mathrm{~h})$, the RF signal was recorded.

and "intact" IL. On the other hand, the nonvolatile, solid decomposition products probably do not contribute to the dielectric and resistive losses and are therefore not covered by the RF method. The latter method detects the portion of "intact" IL on the carrier.

Simulation of the Thermal Decomposition Supported [BMIM][DMP]. Using the results of the TG analysis and the RF-based method, a model for the description of thermal decomposition of supported [BMIM][DMP] is presented below. It is assumed that, in addition to gaseous products, solid degradation products are formed during the IL decomposition. The formed solid is decomposed into gaseous products at higher temperatures in a further decomposition step. Figure 5 shows the model schematically.

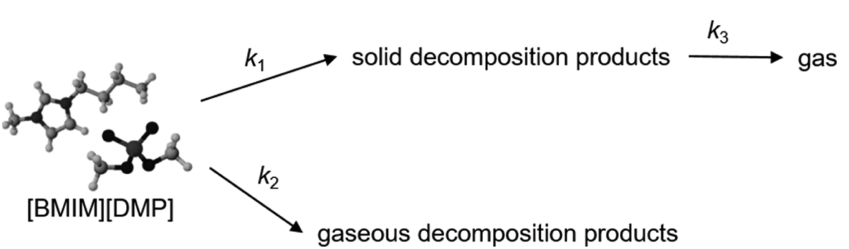

Figure 5. Schematic representation of the model of thermal decomposition of supported [BMIM][DMP]. 
The solid decomposition products are formed with the rate constant $k_{1}$, the gaseous products are formed with $k_{2}$, and the solid products are further decomposed with $k_{3}$. For all three steps, a first-order reaction (with regard to the IL and the solid decomposition products, respectively) is assumed. The determination of the rate of IL decomposition and thus of the residual mass of "intact" IL $m_{\mathrm{IL}}$ is possible by eq 3 , and the rate/mass of the solid products $m_{\text {solid,formed }}$ is obtained by eq 4. ${ }^{21}$ Because it is assumed that a distinction between the "intact" IL and its solid degradation products is not possible by thermogravimetric measurements, $m_{\mathrm{TG}}$ results from the sum of $m_{\mathrm{IL}}$ and $m_{\text {solid,formed }}$ (equation 5). All of the rate constants depend on the temperature according to eq $6 .^{21}$

$$
\begin{aligned}
& \frac{\mathrm{d} m_{\mathrm{IL}}}{\mathrm{d} t}=-\left(k_{1}+k_{2}\right) \cdot m_{\mathrm{IL}}(t) \\
& \frac{\mathrm{d} m_{\text {solid,formed }}}{\mathrm{d} t}=k_{1} \cdot m_{\mathrm{IL}}(t)-k_{3} \cdot m_{\text {solid,formed }}(t) \\
& m_{\mathrm{TG}}=m_{\mathrm{IL}}(t)+m_{\text {solid,formed }}(t) \\
& k_{\mathrm{i}}=k_{0, \mathrm{i}} \cdot \mathrm{e}^{-E_{\mathrm{A}, \mathrm{i}} / R \cdot T}
\end{aligned}
$$

$k_{\mathrm{i}}$ describes the decomposition rate constants, $E_{\mathrm{A}, \mathrm{i}}$ is the activation energies, $k_{0, \mathrm{i}}$ is the pre-exponential factors, $T$ is the temperature in $\mathrm{K}$, and $R$ is the ideal gas constant. These four equations can be used to describe the thermal decomposition of supported [BMIM][DMP]. The three pre-exponential factors and the three activation energies must be determined. This is done by evaluating the three different decomposition experiments, schematically shown in Figure 6. Using the RFbased method, the mass of the "intact" IL can be determined

a) isothermal decomposition test, radio frequency-based method

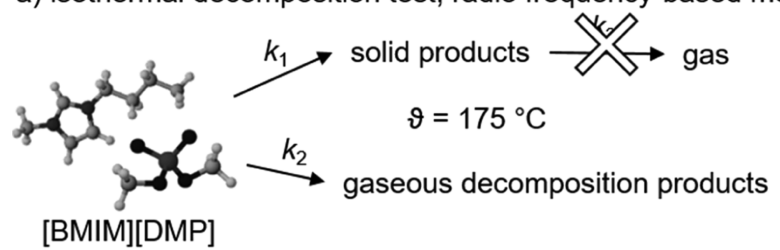

b) isothermal decomposition test, thermogravimetric analysis

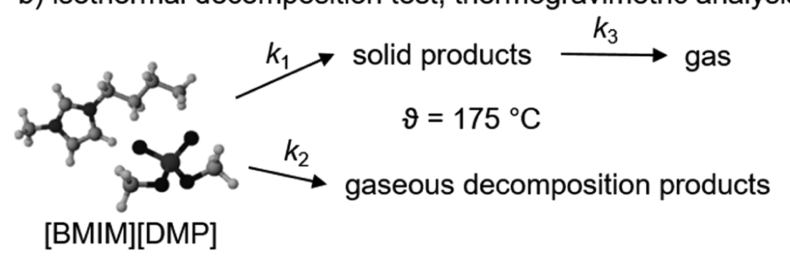

c) non-isothermal decomposition test in a thermobalance

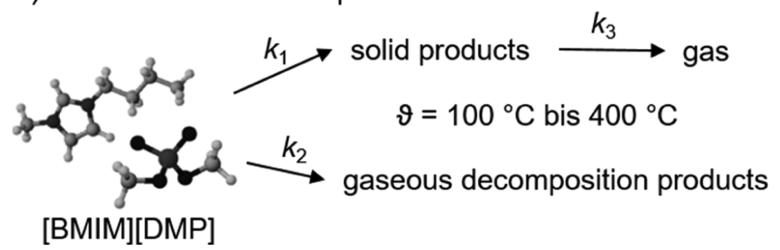

Figure 6. Schematic representation of the decomposition tests for modeling the thermal decomposition of supported [BMIM][DMP]: (a) isothermal decomposition test by the RF-based method; (b) isothermal decomposition test by thermogravimetric analysis; and (c) non-isothermal decomposition test by thermogravimetric analysis. over time, whereas the solid decomposition products are not detected. Therefore, in this case, the decomposition of the solid degradation products does not have to be taken into account $\left(k_{3}=0\right)$ and the sum of $k_{1}$ and $k_{2}$ can be determined for a temperature of $175{ }^{\circ} \mathrm{C}$ (Figure 6a).

In contrast to the RF method, the degradation of solid products must be considered in thermogravimetric measurements because this method cannot distinguish between the "intact" IL and its solid decomposition products (Figure 6b). Thus, it detects the sum of both masses. The rate constants of all three processes at $175^{\circ} \mathrm{C}$ can be determined using eqs $3-5$. In the last step, a non-isothermal thermogravimetric test (Figure $6 \mathrm{c}$ ) is used to determine the pre-exponential factors as well as the activation energies using eqs $3-6$. The results of the isothermal modeling are used as boundary conditions.

The sample masses measured using TG analysis $\left(m_{\mathrm{TG} \text {,meas }}\right.$ filled symbols $)$ and the RF-based method ( $m_{\mathrm{RF} \text { meas }}$, unfilled symbols) are compared in Figure 7 with the modeled values of $m_{\mathrm{IL}, \bmod }, m_{\text {solid,formed,mod }}$ and $m_{\mathrm{TG}, \bmod }$.

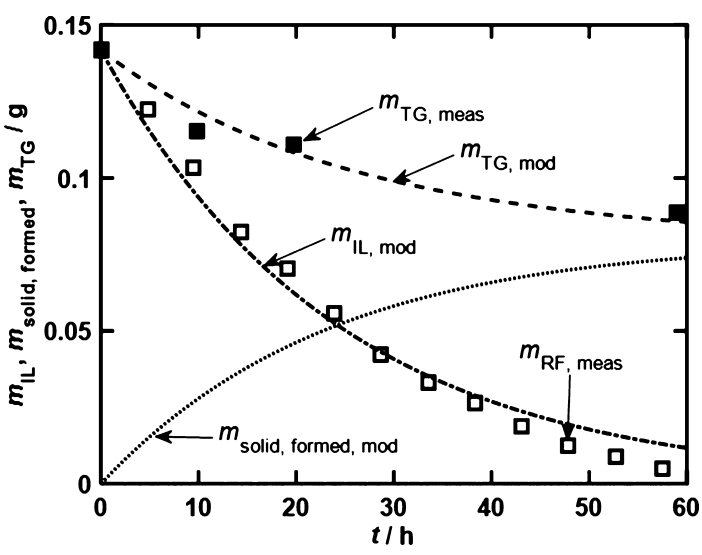

Figure 7. Course of the IL mass during the thermal decomposition of supported [BMIM][DMP] at $175{ }^{\circ} \mathrm{C}$, measured with the RF-based method (unfilled squares) and TG analysis (filled squares). In addition, the modeled values are shown.

The modeled IL mass, as well as the mass of "intact" IL measured using the RF-based method, decreases over the entire test time. Here, the simulated course fits nicely with the measured values, and the sum of $k_{1}$ and $k_{2}$ can be determined to $1.2 \times 10^{-5} \mathrm{~s}^{-1}\left(175{ }^{\circ} \mathrm{C}\right)$. Already at the beginning of the experiment, solid degradation products are produced by the decomposition of the IL [BMIM][DMP] (see Figure 7). The sum of the masses of the solid products and of the "intact" IL corresponds to the signal of the thermobalance (filled symbols, Figure 7). The two isothermal experiments can be well described by the model; the determined rate constants are found in Table 1.

The measured (squares) and modeled (dashed line) courses during a non-isothermal TG examination are shown in Figure 8. Figure $8 \mathrm{a}$ shows the mass $m_{\mathrm{TG}}$ and Figure $8 \mathrm{~b}$ its derivative $\mathrm{d} X / \mathrm{d} t$. The rate constants at $175{ }^{\circ} \mathrm{C}$ from the two isothermal

Table 1. Kinetic Parameters of the Thermal Decomposition of Supported [BMIM] [DMP] at $175^{\circ} \mathrm{C}$

$$
\begin{array}{ll}
k_{1}\left(175^{\circ} \mathrm{C}\right) & 6.7 \times 10^{-6} \mathrm{~s}^{-1} \\
k_{2}\left(175^{\circ} \mathrm{C}\right) & 4.8 \times 10^{-6} \mathrm{~s}^{-1} \\
k_{3}\left(175^{\circ} \mathrm{C}\right) & 1.7 \times 10^{-7} \mathrm{~s}^{-1}
\end{array}
$$



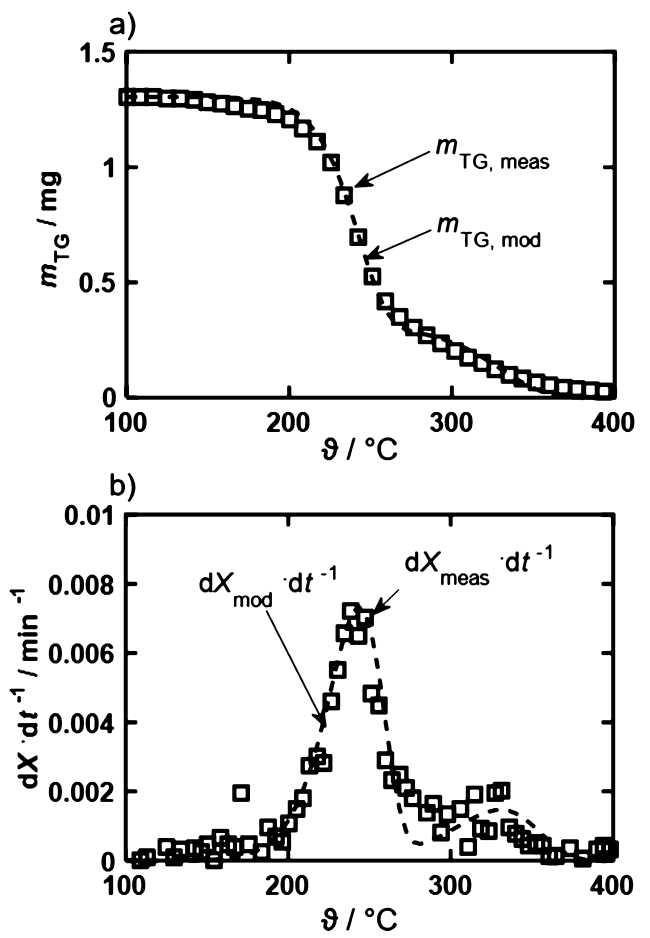

Figure 8. Comparison of (a) IL mass and (b) its derivative with respect to time of a thermogravimetric analysis of supported [BMIM][DMP] (squares) and simulated values (dashed line), heating rate $=0.5 \mathrm{~K} \mathrm{~min}^{-1}, 300 \mathrm{~mL} \mathrm{~min}^{-1}$ nitrogen. For a better representation, a different number of measuring points have been entered in both diagrams.

experiments serve as boundary conditions for the modeling. The course of $\mathrm{d} X / \mathrm{d} t$ shows two maxima, indicating two different decomposition processes. This has already been shown in Figure 2. At temperatures $<250{ }^{\circ} \mathrm{C}$, only the direct decomposition of IL to gaseous products is visible, whereas at higher temperatures, the already formed solid decomposition products of IL decompose to gaseous substances. Because TG cannot distinguish between the mass of "intact" IL and the mass of solid degradation products, the sum of the masses $m_{\mathrm{IL}}$ and $m_{\text {solid,formed }}$ is shown in Figure 8 . With the help of the model, the measured values can be well reproduced. A list of the kinetic parameters of the model is found in Table 2 .

Table 2. Kinetic Parameters of the Thermal Decomposition of Supported [BMIM] $[\mathrm{DMP}]^{a}$

$\begin{array}{ll}E_{\mathrm{A}, 1} & 78 \mathrm{~kJ} \mathrm{~mol}^{-1} \\ E_{\mathrm{A}, 2} & 131 \mathrm{~kJ} \mathrm{~mol}^{-1} \\ E_{\mathrm{A}, 3} & 112 \mathrm{~kJ} \mathrm{~mol}^{-1} \\ k_{0,1} & 9.1 \times 10^{3} \mathrm{~s}^{-1} \\ k_{0,2} & 9.2 \times 10^{9} \mathrm{~s}^{-1} \\ k_{0,3} & 1.7 \times 10^{6} \mathrm{~s}^{-1}\end{array}$

${ }^{a}$ For the meaning of $k_{0}$ and $E_{\mathrm{A}}$, refer to eq 6 .

Figure 9 gives a closer look how the masses evolve with temperature according to the model. Solid degradation products are formed by the decomposition of [BMIM] [DMP] at a temperature above $150{ }^{\circ} \mathrm{C}$. This leads to an increase of $m_{\text {solid,formed,mod }}$ up to $250{ }^{\circ} \mathrm{C}$. Therefore, at temperatures below $200{ }^{\circ} \mathrm{C}$, the mass of the "intact" IL is decisive. Above $270{ }^{\circ} \mathrm{C}$,

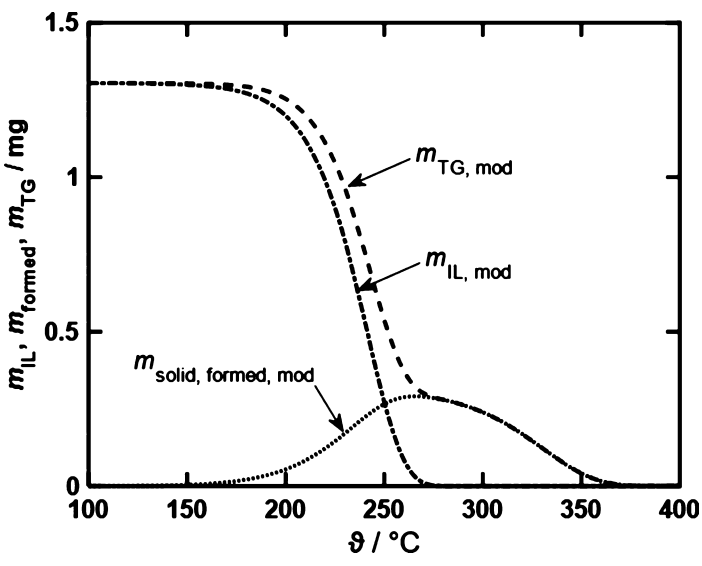

Figure 9. Masses of intact IL $\left(m_{\mathrm{IL}, \mathrm{mod}}\right)$ and solid decomposition products $\left(m_{\text {solid,formed,mod }}\right)$ and their sum $\left(m_{\mathrm{TG}, \mathrm{mod}}\right)$ during a nonisothermal decomposition experiment of supported [BMIM][DMP] in a thermobalance, as derived by the model. Heating rate $=0.5 \mathrm{~K}$

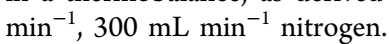

no "intact" IL is present and $m_{\mathrm{TG} \text {,mod }}$ only represents the mass of solid degradation products.

The presented model represents well the course of mass reduction during the thermal decomposition of supported $[\mathrm{BMIM}][\mathrm{DMP}]$ and supports the thesis of the formation of solid decomposition products. Furthermore, the two isothermal and the non-isothermal decomposition experiments were used to determine the kinetic parameters. The second thesis that the RF-based method only detects the portion of "intact" IL is also confirmed by the simulation.

Influence of Thermal Decomposition of [BMIM][DMP] on Activity and Selectivity of the Pd-SCILL-Catalyst. Figure 10 shows both the influence of the IL coating and (for a given pore filling degree of $20 \%$ ) of the thermal decomposition ( $35 \mathrm{~h}$ at $175^{\circ} \mathrm{C}$ ) of the IL layer on the activity and selectivity of the SCILL-Pd-catalyst. The butadiene conversion $U_{\text {butadiene }}$ as a function of the modified residence time $\tau_{\text {mod }}^{\prime}$ is shown in Figure 10a. For all three catalysts, the butadiene conversion increases with the residence time. However, at a given modified residence time, the butadiene conversion of the ILcoated Pd catalyst is significantly lower than that without IL and the conversion is further drastically reduced by the thermal IL decomposition. The selectivity to the butenes $S_{\Sigma \text { butene }}$ as a function of the butadiene conversion is shown in Figure 10b. The two IL-coated catalysts have a selectivity to the butenes of $100 \%$ independent of the butadiene conversion.

Only for the pure Pd catalysts (without IL, open squares), high butadiene conversions lead to the formation of butane. No influence of the thermal decomposition of [BMIM] [DMP] on the butene selectivity can be observed. The increase in the butene selectivity and the decreasing activity of the Pd catalyst by an IL coating agree with the result of a previous work by Barth. ${ }^{20}$ She explains this effect by competing adsorption on the palladium surface. Butadiene binds preferentially compared to the IL [BMIM][DMP], and butene produced during the reaction is replaced by both substances. Thus, the IL layer prevents the subsequent hydrogenation of butene to butane.

Tourillon et al. investigated the adsorption enthalpies of 1,3butadiene and 1-butene on various active metals. ${ }^{22}$ 1,3Butadiene has a higher adsorption enthalpy on palladium than 1-butene. Thus, butene desorbs from the palladium surface and cannot adsorb again. Further isomerization of the 

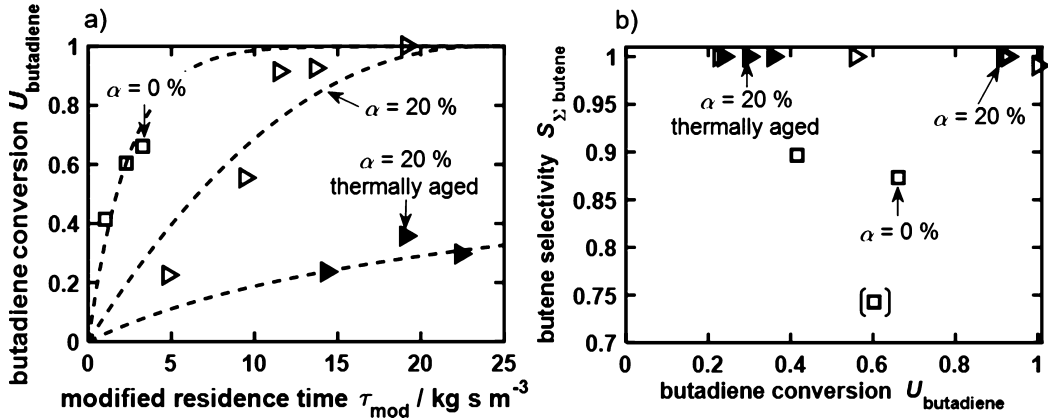

Figure 10. Influence of the IL coating and the thermal decomposition $\left(35 \mathrm{~h}, 175{ }^{\circ} \mathrm{C}\right)$ of the IL layer on (a) butadiene conversion $\left(U_{\text {butadiene }}\right)$ over the modified residence time $\left(\tau_{\text {mod }}^{\prime}\right)$ and (b) selectivity to the butenes $\left(S_{\Sigma \text { butene }}\right)$ in dependence of the butadiene conversion $\left(U_{\text {butadiene }}\right)$, open squares: Pd catalyst without IL, open triangles: Pd catalyst coated with IL $(\alpha=20 \%)$, and filled triangles Pd catalyst coated with IL and thermal aged at $175{ }^{\circ} \mathrm{C}$ for $35 \mathrm{~h} ; 0.3 \mathrm{wt} \% \mathrm{Pd}, \alpha_{0}=20 \%, \theta_{\text {hydrogenation }}=50{ }^{\circ} \mathrm{C}, m_{\text {cat }}=240-900 \mathrm{mg}, p=1$ bar, $c_{\text {butadiene }}=0.5 \%, c_{\mathrm{H}_{2}}=10 \%$, balance: nitrogen.

formed butenes is therefore suppressed. ${ }^{20}$ However, this positive effect of the IL coating on the selectivity is counterbalanced by the lower activity that is caused by a lower Brunauer-Emmett-Teller (BET) surface area of the SCILL-catalyst. The BET surface area decreased from 298 to $186 \mathrm{~m}^{2} \mathrm{~g}^{-1}$ after being coated with IL $(\alpha=20 \%)$.

To identify the reason for the lower activity after thermal decomposition of [BMIM] [DMP] on a Pd catalyst, the course of the apparent pore filling degree during the decomposition experiment was examined in more detail (see Figure 11). The

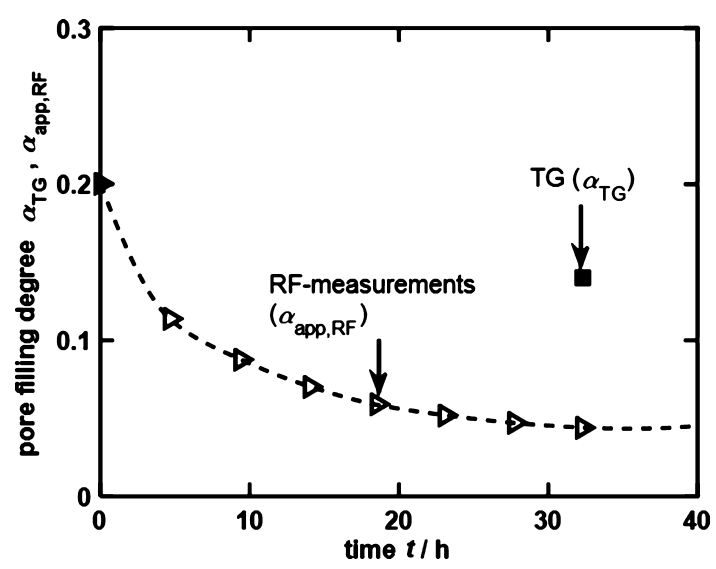

Figure 11. Course of the apparent pore filling degree $\alpha_{\mathrm{app}, \mathrm{RF}}$ (measured at $20{ }^{\circ} \mathrm{C}$ ) during the thermal decomposition (at 175 $\left.{ }^{\circ} \mathrm{C}\right)$ of $[\mathrm{BMIM}][\mathrm{DMP}]$ supported on a Pd catalyst $(0.3 \mathrm{wt} \% \mathrm{Pd}, \alpha=$ $20 \%)$ measured using the RF-based measurement technique (triangles). In addition, after the experiment, the degree of pore filling was determined in a thermobalance (square).

apparent degree of pore filling was again determined by the RF-based measurement technique. After completing the test, the powder sample was examined in a thermobalance and the mass loss in air was determined. $\alpha_{\text {app,RF }}$ decreases considerably at the beginning and more slowly with time. After $35 \mathrm{~h}$, the apparent degree of pore filling (and thus the amount of still intact IL) had dropped from initially 20 to $4 \%$. By means of TG, however, the degree of pore filling was determined to $14 \%$ after thermal decomposition. As in the decomposition experiment without palladium (Figure 4), the portion of "intact" IL on the carrier is overestimated by TG because solid decomposition products are formed in addition to volatile compounds. In contrast, the solid products are inert to the electrical measurement and do not contribute to the losses $\varepsilon^{\prime \prime}$.
Thus, the RF-based analysis records only the portion of "intact" IL on the carrier.

As shown in Figure 10, the formation of solid decomposition products also affects the activity of the Pd catalyst. A relative high modified residence time of $25 \mathrm{~kg}_{\text {cat }} \mathrm{s} \mathrm{m}^{-3}$ is needed to reach a butadiene conversion with the thermally treated catalyst of $30 \%$, whereas this conversion is already reached with the fresh, untreated catalyst at a residence time of about 4 $\mathrm{kg}_{\text {cat }} \mathrm{s} \mathrm{m}^{-3}$. Hence, the activity had dropped by a factor of about 6 , which nicely corresponds to the reduction of the pore filling degree with intact IL from 20 to $4 \%$ (reduction by a factor 5), as measured by the RF analysis (Figure 10). Therefore, most probably, the solid decomposition products, which require a space corresponding to a filling degree of about $10 \%$ (difference of $\alpha_{\mathrm{TG}}$ and $\alpha_{\mathrm{app}, \mathrm{RF}}$ after 35 hours of treatment in $\mathrm{N}_{2}$ flow at $175{ }^{\circ} \mathrm{C}$, see Figure 10), deactivate the catalyst to a large extent, but the remaining surface, where intact IL and hence a remaining part of the SCILL-catalyst are present and active, still catalyzes the butadiene hydrogenation. This also explains why the selectivity to the butenes is still $100 \%$ (as in the case of the fresh SCILL-catalyst) (see Figure $10 \mathrm{~b})$.

On contrary to the RF-based analysis, TG provides only limited information about the processes during decomposition of supported ILs, that is, to what extent solid residues and/or volatile gaseous products are formed. After a thermal aging of $35 \mathrm{~h}$ at $175^{\circ} \mathrm{C}$, the result of the TG analysis indicates only a relative small change of the IL pore filling degree from 20 to $14 \%$. Accordingly, neither the selectivity to butenes nor the activity of the Pd catalyst should change significantly. However, according to Figure 10, this is not the case. On the other hand, the RF-based method detects nicely the portion of "intact" IL in a contactless way and operando. After a decomposition time of $35 \mathrm{~h}$, an apparent pore filling degree of $4 \%$ can be determined and therefore only $20 \%$ of the initial IL $\left(\alpha_{0}=20 \%\right)$ is still left on the Pd catalyst. As discussed, this lowers the activity of the catalyst at still constant selectivity as long as enough "intact" IL is still present on the catalyst. The solid decomposition products of the IL [BMIM][DMP] seem to bind on the surface and hinder the adsorption (and reaction) both of butadiene and butene on the porous surface. NMR measurements support this hypothesis.

NMR Measurements. NMR spectra were obtained from both the freshly supported IL [BMIM][DMP] and from a thermally aged sample $\left(60 \mathrm{~h}, 175{ }^{\circ} \mathrm{C}\right)$. Figure 12 shows the ${ }^{1} \mathrm{H}$-liquid-NMR spectrum of (a) the pure IL [BMIM][DMP], 


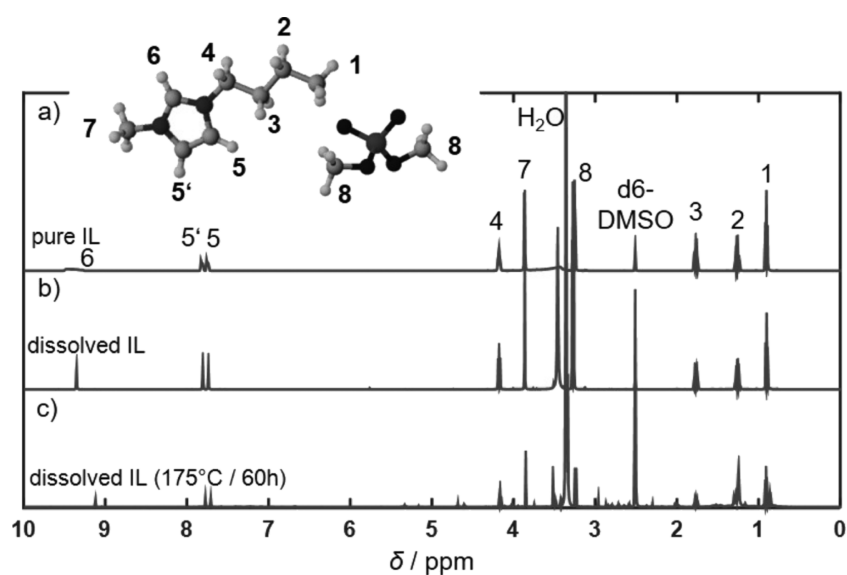

Figure 12. ${ }^{1} \mathrm{H}$-liquid-NMR spectrum of (a) pure IL, (b) IL dissolved from the carrier, and (c) thermally aged IL dissolved from the carrier, solvent: DMSO- $d_{6}$.

(b) the IL dissolved from the porous carrier silica with dichloromethane (DCM), and (c) the thermally aged and subsequently dissolved IL from the porous carrier silica. The resonance peaks of the pure IL could be matched to the individual groups of the anion and the cation, respectively ${ }^{23}$ (see Figure 12a). The spectrum of the IL dissolved from the carrier (Figure 12b) shows no or hardly any differences to the spectrum of the pure IL. Analysis of the supported IL using ${ }^{1} \mathrm{H}$-liquid-NMR spectroscopy is therefore possible. In contrast, the spectrum of thermally aged IL dissolved from the carrier (Figure 12c) shows some changes.

On the one hand, an increase in the number of resonance peaks and a further splitting of the resonance peaks of the methyl/methylene groups 1-3 are recognizable. On the other hand, resonance peak 6 of the imidazole ring is shifted to lower $\delta$-values and resonance peak 8 of the methyl group of the anion decreases in height relative to the other peaks. These deviations indicate a change in the chemical structure of the anion and the cation of the coated IL under thermal aging. In addition, several minor resonance peaks appear in the spectrum. They may indicate decomposition products, but could not be assigned. It should be noted that only those compounds that can be dissolved from the carrier with DCM appear in the spectrum. Any decomposition product that remains on the carrier is not visible.

To gain further insight into the chemical nature of the thermally aged $\mathrm{IL},{ }^{31} \mathrm{P}$-solid state NMR spectra of four different samples were recorded (Figure 13):

(a) $[$ BMIM $][D M P]$ supported on silica

(b) $[\mathrm{BMIM}][\mathrm{DMP}]$ supported on silica, with the IL partially leached out from the support with DCM (the IL could not be completely removed)

(c) $[\mathrm{BMIM}][\mathrm{DMP}]$ supported on silica, thermally aged at $175{ }^{\circ} \mathrm{C}$ for $60 \mathrm{~h}$

(d) $[$ BMIM $][$ DMP $]$ supported on silica, thermally aged at $175^{\circ} \mathrm{C}$ for $60 \mathrm{~h}$ and then partially leached out from the support with DCM (the IL could not be completely removed)

All four spectra show a resonance peak at a chemical shift of $2 \mathrm{ppm}$. This peak can be assigned to the phosphate of the anion. In addition, a smaller peak at $-9 \mathrm{ppm}$ is weakly visible in the spectra of the IL leached out from the support (Figure $13 b)$ and clearly visible in the spectra of the thermally aged

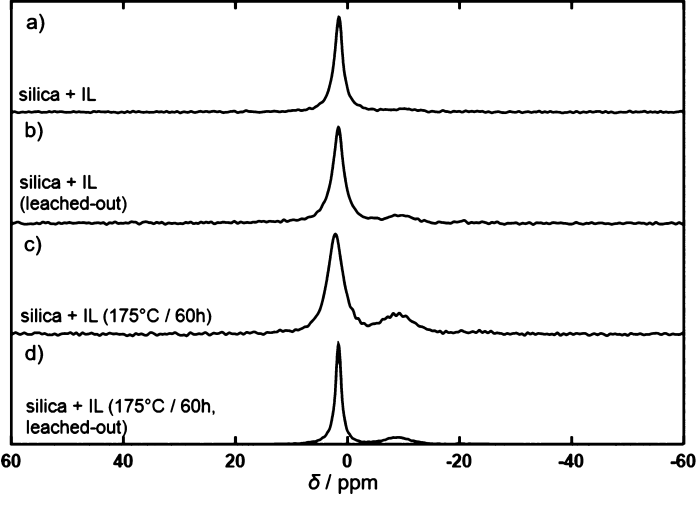

Figure 13. ${ }^{31} \mathrm{P}$-solid NMR spectrum of (a) freshly prepared, supported IL, (b) supported IL after removal of a portion of the IL from the carrier, (c) thermally aged supported IL, and (d) thermally aged supported IL after removal of a portion of the IL.

samples (Figure 13c,d). This indicates a further phosphate compound that is slightly existing in the fresh sample but arises by thermal decomposition.

Kohli and Blanchard investigated $\mathrm{POCl}_{3}$ on silica using ${ }^{31} \mathrm{P}$ solid state NMR and observed the formation of two resonance peaks at $-0.6 \mathrm{ppm}$ and $-11.8 \mathrm{ppm}$. $^{24}$ They assigned the peaks to phosphor that is bound physically $(-0.6 \mathrm{ppm})$ and chemically $(-11.8 \mathrm{ppm})$ on the support. This finding could lead to the interpretation that the resonance peak at $-9 \mathrm{ppm}$ in our ${ }^{31} \mathrm{P}$ spectra is caused by a chemically, strongly bound phosphor compound that is formed during thermal aging.

A phosphor compound strongly bound to the carrier would not or hardly contribute to electric losses $\varepsilon^{\prime \prime}$ because of its strongly reduced mobility. ${ }^{25}$ This effect might be further increased by a possible loss of its ionic character during thermal aging. In addition, the strongly bound phosphor compound would hinder adsorption of the substances 1,3butadiene and butene. This would in turn result in a lower activity of the thermally aged SCILL-catalyst combined with unchanged high selectivity to the butenes.

\section{CONCLUSIONS}

In this work, it could be shown that the RF-based measurement technology is suitable to analyze the thermal decomposition of supported [BMIM][DMP]. Compared to TG, it has the advantage that it can be conducted without contact and operando. Furthermore, the RF-based method allows a differentiation between "intact" IL and its solid or liquid decomposition products that remain on the carrier. A distinction between solid or liquid products is not possible, especially because there are only one or a few molecular layers on the carrier. The course of the real part of the permittivity $\varepsilon^{\prime}$ during a thermal decomposition experiment shows no significant change. Therefore, an almost constant sample volume can be assumed. The course of the losses $\varepsilon^{\prime \prime}$ indicates, in contrast, changes in the electrical properties. As a conclusion, a changed structure of the supported IL can be deduced, whereas a thermobalance only analyzes the pure mass loss. With the help of a model, it could be confirmed that thermal decomposition of supported [BMIM][DMP] produces solid as well as gaseous decomposition products. The solid products negatively influence the activity of a Pd-SCILLcatalyst. They bind on the catalyst surface and thus hinder the 
hydrogenation of 1,3-butadiene. A distinction between "intact" IL and solid degradation products is therefore advantageous.

\section{EXPERIMENTAL SECTION}

Measurement Setup and Calculation of the Complex Permittivity. The measurement setup, shown in Figure 14, is

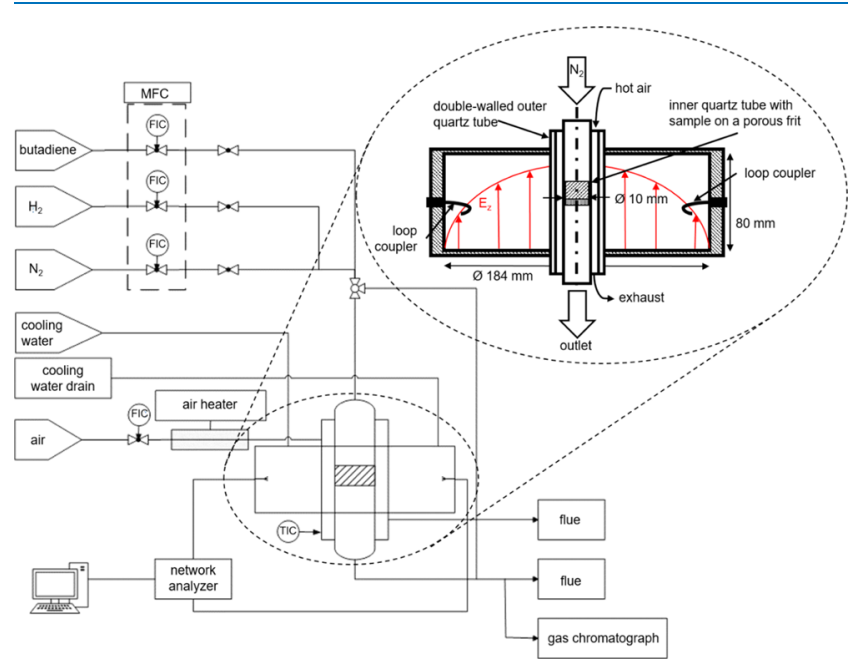

Figure 14. Setup for operando measurements of the electrical parameters in the microwave range of IL-coated Pd catalysts during the selective hydrogenation of butadiene to butene.

used to determine the complex dielectric permittivity and the catalytic activity of the coated $\mathrm{Pd}$ catalyst. It consists of a cylindrical cavity resonator and two concentrically arranged quartz tubes. The catalyst bed (sample) is located on a porous quartz frit in the inner tube. The process gas flows through it. The outer tube is double-walled with an evacuated gap to minimize heat losses. Hot air flows between the two tubes to heat both the sample and the process gas. Two thermocouples are mounted before and after the sample (outside the resonator). The mean value of both thermocouples is assumed as the sample temperature. The temperature difference between both thermocouples is always lower than $20{ }^{\circ} \mathrm{C}$. A gas chromatograph is connected downstream of the reactor to analyze the outlet gas composition. Two loop couplers (inductive antennas) are mounted in the inner resonator wall. They are connected via coaxial cables to a network analyzer (Anritsu VNA MS2028B) and allow to excitate an electromagnetic field as well as to record of the scattering parameters (transmission and reflection).

The aluminum resonator is designed for a certain frequency range that is determined not only by the permittivity of the sample but also by the geometric dimensions of the cavity (inner diameter: $184 \mathrm{~mm}$, height: $80 \mathrm{~mm}$ ). In this study, the first transverse magnetic resonance mode at a frequency of ca. 1.2 $\mathrm{GHz}$ is used because in the position of the sample, its electric field is homogeneous and maximal. ${ }^{26}$ This setup and the fact that all other components in the resonator are made of low-loss quartz allow the complex permittivity of the sample to be determined. Further information on the measurement setup can be found in refs. ${ }^{18,27}$

With a network analyzer, the transmission parameter $S_{21}$, which is the ratio of the complex amplitudes of transmitted and received waves, ${ }^{14}$ is recorded over the excitation frequency. Figure 15 illustrates a transmission spectrum of the empty

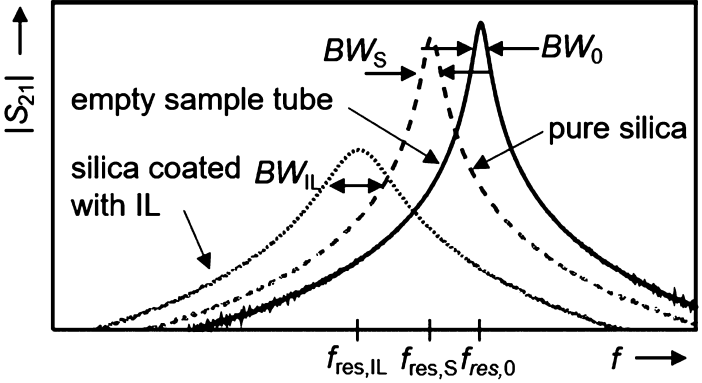

Figure 15. Transmission spectrum of the empty sample tube (index 0 ), of the sample tube filled with uncoated silica (index $S$ ), and the sample tube filled with silica supported with IL (index IL, $\alpha=30 \%$ ).

sample tube (index 0), of a sample tube filled with pure silica (index $S$ ) and filled with silica coated with IL ( $\alpha=30 \%$, index IL). At the resonant frequency, the absolute value of the transmission parameter is maximal. In addition, the half-value bandwidth ( $3 \mathrm{~dB}$ bandwidth) can also be determined from the spectrum and the complex permittivity $\varepsilon$ can then be calculated using eqs 7-9.

$$
\begin{aligned}
& \underline{\varepsilon}=\varepsilon^{\prime}-\mathrm{j} \varepsilon^{\prime \prime} \\
& \varepsilon^{\prime}-1=\frac{2 \cdot V_{\text {eff }}}{V_{\text {sample }}} \cdot \frac{\Delta f_{\text {res }}}{f_{\text {res }, 0}} \\
& \varepsilon^{\prime \prime}=\frac{V_{\text {eff }}}{V_{\text {sample }}} \cdot \frac{\Delta \mathrm{BW}}{f_{\text {res }, 0}}
\end{aligned}
$$

$\varepsilon^{\prime}$ represents the real part of the complex permittivity and is a measure for the polarization of a material in the electric field. ${ }^{28}$ $\varepsilon^{\prime \prime}$ denotes the imaginary part of the complex permittivity and describes the dielectric and resistive losses. ${ }^{28} f_{\text {res }, 0}$ stands for the resonant frequency of the empty sample tube, and $\Delta f_{\text {res }}$ stands for the shift of the resonant frequency after introducing a sample into the sample tube. $\Delta \mathrm{BW}$ is the corresponding widening of the bandwidth, $j$ is the imaginary unit, and $V_{\text {sample }}$ describes the sample volume, determined by a gas pycnometer (Micromeritics AccuPyc 1330). $V_{\text {eff }}$ is a calibration variable and was determined before each measurement by means of a polytetrafluorethylene cylinder of known permittivity $\left(\varepsilon^{\prime}=\right.$ 2.1) by applying eq $8 .^{26}$

Preparation and Characterization of Samples. Samples are prepared by wetness impregnation. Silica $150 \AA$ (Sigma-Aldrich) was used as the porous carrier. In a first step, the silica was (if necessary) coated with the active component palladium and, in a second step, the IL 1-butyl-3methylimidazolium dimethylphosphate ([BMIM][DMP], Iolitec, purity 99\%) was immobilized on the heterogeneous catalyst. Further details on the preparation conditions are given below. The pore volume, the BET surface area, and the mean pore diameter of all prepared samples were determined by nitrogen adsorption measurements (Gemini V, Micromeritics). Before each coating, the water content of the pure IL was measured by titration (Karl Fischer titrator $831 \mathrm{KF}$, Metrohm). The average value of three consecutive titrations was always less than $1 \mathrm{wt} \%$. Further parameters of the porous carrier and the IL are found in Table 3.

To prepare the IL-supported Pd catalysts, the required amount of carrier material was mixed with the corresponding amount of the precursor palladium(II)nitrate hydrate (Alfa 
Table 3. Material Parameters of the Porous Carrier and the Used IL

\begin{tabular}{|c|c|}
\hline \multicolumn{2}{|l|}{ silica $150 \AA$ powder } \\
\hline pore surface $A_{\mathrm{BET}}$ & $308 \mathrm{~m}^{2} \mathrm{~g}^{-1}$ \\
\hline specific pore volume $V_{\text {pore }, 0}$ & $1.05 \mathrm{~cm}^{3} \mathrm{~g}^{-1}$ \\
\hline mean pore diameter $d_{\text {pore, } \mathrm{m}}$ & $14 \mathrm{~nm}$ \\
\hline diameter of the particles $d_{\mathrm{p}}$ & $250 \mu \mathrm{m}$ \\
\hline \multicolumn{2}{|c|}{ 1-butyl-3-methylimidazolium dimethylphosphate ([BMIM][DMP]) } \\
\hline density $\rho_{\mathrm{IL}}$ & $1.18 \mathrm{~g} \mathrm{~cm}^{-120}$ \\
\hline molar mass $M_{\mathrm{IL}}$ & $264 \mathrm{~g} \mathrm{~mol}^{-120}$ \\
\hline vapor pressure (taken from $[\mathrm{DMIM}][\mathrm{DMP}]) p_{\text {vap }, \mathrm{IL}}$ & $\begin{array}{l}6.7 \times 10^{-6} \mathrm{~Pa} \\
(373 \mathrm{~K})^{20}\end{array}$ \\
\hline & $0.2 \mathrm{mPa}(410 \mathrm{~K})^{20}$ \\
\hline $\begin{array}{l}\text { decomposition temperature } T_{\text {decomposition }} \\
\text { (mass loss } 1 \% / \text { month) }\end{array}$ & $137^{\circ} \mathrm{C}^{20}$ \\
\hline water content & $<1$ wt $\%$ \\
\hline
\end{tabular}

Aesar, 39\% Pd) in acetone that served as a solvent. After slowly removing of the acetone, a drying step $\left(100{ }^{\circ} \mathrm{C}\right)$ was carried out in a rotary evaporator under high vacuum. The powder was then calcined in air and reduced with hydrogen. After determination of the resulting palladium content using inductively coupled plasma-optical emission spectrometry (ICP-OES), the IL was immobilized. Therefore, a given amount of the Pd catalyst was mixed with the corresponding amount of IL in DCM, the DCM was slowly removed, and the powder was dried in a rotary evaporator at $50{ }^{\circ} \mathrm{C}$ under high vacuum. Further information on the preparation is given in Table 4.

\section{Table 4. Preparation Parameter of the Pd Catalyst}

\begin{tabular}{|c|c|}
\hline porous carrier & silica $150 \AA$ \\
\hline precursor & palladium(II)nitrate hydrate \\
\hline solvent & acetone \\
\hline \multirow[t]{4}{*}{ calcination parameter } & air \\
\hline & $1 \mathrm{~K} \mathrm{~min}^{-1}$ \\
\hline & $\theta_{\max }=350^{\circ} \mathrm{C}$ \\
\hline & $4 \mathrm{~h}$ \\
\hline \multirow[t]{4}{*}{ parameter of reduction } & $10 \% \mathrm{H}_{2}$ in $\mathrm{N}_{2}$ \\
\hline & $2 \mathrm{~K} \mathrm{~min}^{-1}$ \\
\hline & $\theta_{\max }=350^{\circ} \mathrm{C}$ \\
\hline & $4 \mathrm{~h}$ \\
\hline
\end{tabular}

The pore filling degree was then determined from all samples using a thermobalance (TG 209 F3 Tarsus, Netzsch, Selb, Germany). The measured values correspond well with the calculated ones from the sample preparation $( \pm 20 \%)$. Before each RF-based measurement, samples were preconditioned in the reactor for $1 \mathrm{~h}$ at $100{ }^{\circ} \mathrm{C}$ under nitrogen to remove any remaining adsorbed water.

Analysis of Thermal Decomposition. In order to analyze the thermal decomposition, the supported IL ( $m_{\text {sample }} \approx 0.5 \mathrm{~g}$ ) was filled into the reactor. After a conditioning phase of $1 \mathrm{~h}$ at $100{ }^{\circ} \mathrm{C}$, the losses $\varepsilon^{\prime \prime}$ of the sample were determined at $20^{\circ} \mathrm{C}$. Then, the reactor was heated to $175{ }^{\circ} \mathrm{C}$ to initiate the decomposition. After $5 \mathrm{~h}$, the reactor was cooled down to 20 ${ }^{\circ} \mathrm{C}$ again and the losses $\varepsilon^{\prime \prime}$ were determined once again. This process cycle was repeated several times. The measurement time at $175{ }^{\circ} \mathrm{C}$ after deduction of the heating and cooling phases was $60 \mathrm{~h}$ ( $35 \mathrm{~h}$, for samples with Pd addition). Because the heating and cooling rates were very high, a possible decomposition of the IL during these times can be neglected. Table 5 summarizes all measuring parameters.

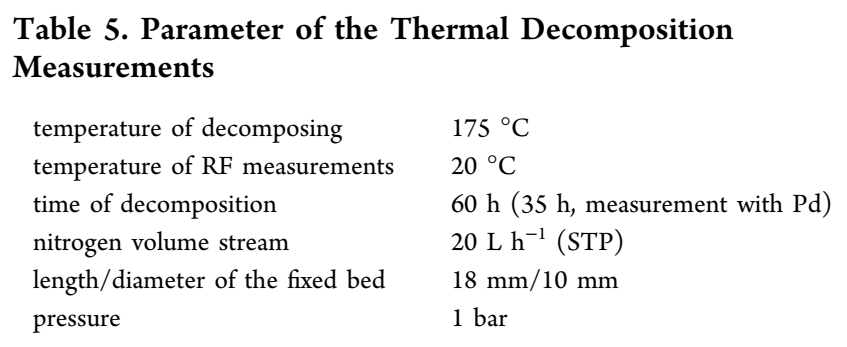

Thermogravimetric measurements were also carried out for validation (Figure 4). For this purpose, after certain times (10, 20 , and $60 \mathrm{~h}$ ), the measurement was interrupted and the entire sample was taken out. A small part of the sample was then used to determine the mass loss in a thermobalance. Subsequently, a fresh sample with identical initial pore filling degree was used for another experiment starting again at time $t=0 \mathrm{~h}$. Altogether, three independent experimental runs generated the three TG data points in Figure 4. The electrical signal was only evaluated during the longest measurement over $60 \mathrm{~h}$.

Selective Hydrogenation of 1,3-Butadiene to Butene. To compare the Pd catalysts with and without an IL loading, the selectivity to the butenes was determined in addition to the butadiene conversion. A gas chromatograph (Varian LHA, model CP-3800) analyzed the composition of the reactant gas and the product gas. Table 6 shows the parameters of the measurement. The palladium content of all used catalysts was 0.3 wt $\%$.

Table 6. Experimental Parameters of the Selective Hydrogenation of Butadiene

$\begin{array}{ll}\text { temperature } & 50{ }^{\circ} \mathrm{C} \\ \text { total pressure } & 1 \mathrm{bar} \\ \text { partial pressure butadiene } & 5 \mathrm{mbar} \\ \text { partial pressure hydrogen } & 100 \mathrm{mbar} \\ \text { palladium content } & 0.3 \mathrm{wt} \%\end{array}$

\section{ASSOCIATED CONTENT}

Supporting Information

The Supporting Information is available free of charge on the ACS Publications website at DOI: 10.1021/acsomega.8b02421.

Diagram of a TG analysis with the carrier gases nitrogen and helium to distinguish between mass loss due to evaporation or due to thermal decomposition (PDF)

\section{AUTHOR INFORMATION}

\section{Corresponding Author}

*E-mail: marie-luise.anke@uni-bayreuth.de.

ORCID $\odot$

Marie-Luise Anke: 0000-0001-6956-0581

\section{Author Contributions}

The manuscript was written with contributions of all authors. All authors have given approval to the final version of the manuscript.

Notes

The authors declare no competing financial interest. 


\section{ACKNOWLEDGMENTS}

The authors are indebted to the German Research Foundation (DFG) for financial support (Je 257/21-1 and Mo 1060/27-1). The authors thank Jörg Gerchau for help with the measurement setup, Birgit Brunner for the ICP-OES analysis, Beate Bojer for the ${ }^{31} \mathrm{P}$-solid state NMR, and Ulrike Lacher for the ${ }^{1} \mathrm{H}$ NMR measurements.

\section{ABBREVIATIONS}

[BMIM][DMP], 1-butyl-3-methylimidazolium dimethylphosphate; [DMIM][DMP], 1,3-dimethylimidazolium dimethylphosphate; [EMIM][NTf ${ }_{2}$, 1-ethyl-3-methylimidazolium bis(trifluoromethylsulfonyl)imide; IL, ionic liquid; Pd, palladium; $\mathrm{RF}$, radio frequency; SCILL, solid catalyst with ionic liquid layer; SCR, selective catalytic reduction; SILP, supported ionic liquid phase; TG, thermogravimetry/thermogravimetric

\section{REFERENCES}

(1) Wasserscheid, P.; Keim, W. Ionic Liquids-New "Solutions" for Transition Metal Catalysis. Angew. Chem., Int. Ed. 2000, 39, 37723789.

(2) Holbrey, J. D.; Rogers, R. D. Physicochemical Properties of Ionic Liquids: Melting Points and Phase Diagrams. In Ionic Liquids in Synthesis; Wasserscheid, P., Welton, T., Eds.; John Wiley \& Sons: Weinheim, 2008; pp 57-72.

(3) Welton, T. Room-Temperature Ionic Liquids. Solvents for Synthesis and Catalysis. Chem. Rev. 1999, 99, 2071-2084.

(4) Wasserscheid, P. Outlook - the Thechnikal Prospect of Supported Ionic Liquid Materials. In Supported Ionic Liquids; Fehrmann, R., Riisager, A., Haumann, M., Eds.; John Wiley \& Sons: Weinheim, 2013; pp 459-465.

(5) Heym, F.; Korth, W.; Thiessen, J.; Kern, C.; Jess, A. Evaporation and Decomposition Behavior of Pure and Supported Ionic Liquids under Thermal Stress. Chem. Ing. Tech. 2015, 87, 791-802.

(6) Riisagera, A.; Fehrmanna, R.; Haumannb, M.; Wasserscheidb, P. Supported ionic liquids: versatile reaction and separation media. Top. Catal. 2006, 40, 91-102.

(7) Kernchen, U.; Etzold, B.; Korth, W.; Jess, A. Solid Catalyst with Ionic Liquid Layer (SCILL) - A New Concept to Improve Selectivity Illustrated by Hydrogenation of Cyclooctadiene. Chem. Eng. Technol. 2007, 30, 985-994.

(8) Barth, T.; Korth, W.; Jess, A. Selectivity-Enhancing Effect of a SCILL Catalyst in Butadiene Hydrogenation. Chem. Eng. Technol. 2016, 40, 395-404.

(9) Mangartz, T.; Häcker, L.; Korth, W.; Kern, C.; Jess, A. Improving the Selectivity to Butene Using a Solid Pd-Catalyst with an Ionic Liquid Laye (SCILL). Oil Gas Eur. Mag. 2014, 130, 84-90.

(10) Supported Ionic Liquids; Fehrmann, R., Riisager, A., Haumann, M., Eds.; John Wiley \& Sons: Weinheim, 2013.

(11) Heym, F.; Kern, C.; Thiessen, J.; Jess, A. Transport Phenomena, Evaporation, and Thermal Stability of Supported Ionic Liquids. In Supported Ionic Liquids; Fehrmann, R., Riisager, A., Haumann, M., Eds.; John Wiley \& Sons: Weinheim, 2013; pp 105143.

(12) Bottom, R. Thermogravimetric Analysis. In Principles and Applications of Thermal Analysis; Gabbott, P., Ed.; Blackwell Publishing: Oxford, 2008; pp 87-118.

(13) Müller, N.; Reiß, S.; Fremerey, P.; Jess, A.; Moos, R. Initial tests to detect quantitatively the coke loading of reforming catalysts by a contactless microwave method. Chem. Eng. Process. 2011, 50, 729731.

(14) Rauch, D.; Fremerey, P.; Jess, A.; Moos, R. In situ detection of coke deposits on fixed-bed catalysts by a radio frequency-based method. Sens. Actuators, B 2013, 181, 681-689.

(15) Dietrich, M.; Hagen, G.; Reitmeier, W.; Burger, K.; Hien, M.; Grass, P.; Kubinski, D.; Visser, J.; Moos, R. Radio-FrequencyControlled Urea Dosing for $\mathrm{NH}_{3}$-SCR Catalysts: $\mathrm{NH}_{3}$ Storage
Influence to Catalyst Performance under Transient Conditions. Sensors 2017, 17, 2746.

(16) Moos, R.; Rauch, D.; Votsmeier, M.; Kubinski, D. Review on Radio Frequency Based Monitoring of SCR and Three Way Catalysts. Top. Catal. 2016, 59, 961-969.

(17) Fremerey, P.; Jess, A.; Moos, R. Why does the Conductivity of a Nickel Catalyst Increase during Sulfidation? An Exemplary Study Using an In Operando Sensor Device. Sensors 2015, 15, 27021-27034.

(18) Anke, M.-L.; Hämmerle, M.; Gerchau, J.; Moos, R.; Jess, A. Radio Frequency-Based In Situ Determination of the Mass Loss of Supported Ionic Liquids. Chem. Eng. Technol. 2017, 40, 1660-1665.

(19) Anke, M.-L.; Hämmerle, M.; Jess, A.; Moos, R. Radio frequency- and impedance-based sensing of ionic liquids supported on porous carriers and their limitations. Sens. Actuators, B 2018, 273, 1564-1571.

(20) Barth, T. Selektivhydrierung von 1,3-Butadien an mit ionischen Fluiden beschichteten heterogenen Katalysatoren. PhD Thesis, Universität Bayreuth, Bayreuth, 2016.

(21) Jess, A.; Wasserscheid, P. Chemical Technology; John Wiley \& Sons: Weinheim, 2013; pp 200-216.

(22) Tourillon, G.; Cassuto, A.; Jugnet, Y.; Massardier, J.; Bertolini, J. C. Buta-1,3-diene and but-1-ene chemisorption on $\mathrm{Pt}(111)$, $\operatorname{Pd}(111), \operatorname{Pd}(110)$ and $\mathrm{Pd}_{50} \mathrm{Cu}_{50}(111)$ as studied by UPS, NEXAFS and HREELS in relation to catalysis. J. Chem. Soc., Faraday Trans. 1996, 92, 4835-4841.

(23) Kuhlmann, E.; Himmler, S.; Giebelhaus, H.; Wasserscheid, P. Imidazolium dialkylphosphates-a class of versatile, halogen-free and hydrolytically stable ionic liquids. Green Chem. 2007, 9, 233-242.

(24) Kohli, P.; Blanchard, G. J. Probing Interfaces and Surface Reactions of Zirconium Phosphate/Phosphonate Multilayers Using ${ }^{31}$ P NMR Spectrometry. Langmuir 2000, 16, 695-701.

(25) Chen, L. F.; Ong, C. K.; Neo, C. P.; Varaden, V. V.; Varaden, V. K. Microwave Electronics: Measurements and Materials Characterisation; John Wiley \& Sons: West Sussex, 2004; pp 11-16.

(26) Slocombe, D.; Porch, A.; Bustarret, E.; Williams, O. A. Microwave properties of nanodiamond particles. Appl. Phys. Lett. 2013, 102, 244102.

(27) Dietrich, M.; Rauch, D.; Porch, A.; Moos, R. A laboratory test setup for in situ measurements of the dielectric properties of catalyst powder samples under reaction conditions by microwave cavity perturbation: set up and initial tests. Sensors 2014, 14, 16856-16868.

(28) Dietrich, M.; Rauch, D.; Simon, U.; Porch, A.; Moos, R. Ammonia storage studies on H-ZSM-5 zeolites by microwave cavity perturbation: Correlation of dielectric properties with ammonia storage. J. Sens. Sens. Syst. 2015, 4, 263-269. 